OPEN ACCESS

Edited by:

Utpal S. Bhalala,

Driscoll Children's Hospital,

United States

Reviewed by:

Anwar Baban,

Bambino Gesù Children's Hospital, Scientific Institute for Research,

Hospitalization and Healthcare (IRCCS), Italy

Howard Prentice

Florida Atlantic University,

United States

*Correspondence:

Yahya H. AlMashham

yalmashham@gmail.com

Specialty section:

This article was submitted to

Pediatric Cardiology,

a section of the journal

Frontiers in Cardiovascular Medicine

Received: 02 September 2021 Accepted: 27 December 2021

Published: 11 February 2022

Citation:

Tamimi OR, AlGonaid OA, AlMashham $\mathrm{YH}$ and Almashham AY (2022) Pediatric Cardiologist's View on

Centralization of Pediatric Cardiology Services: A Questionnaire Survey.

Front. Cardiovasc. Med. 8:769923.

doi: 10.3389/fcvm.2021.769923

\section{Pediatric Cardiologist's View on Centralization of Pediatric Cardiology Services: A Questionnaire Survey}

\author{
Omar R. Tamimi, Omer A. AlGonaid, Yahya H. AlMashham* and \\ Abdulrahman Y. Almashham
}

King Fahad Medical City, Riyadh, Saudi Arabia

The population of the Kingdom of Saudi Arabia (KSA) exceeding 35 million people and in the presence of a non-structured increase in the number of pediatric cardiac centers, we expect to face some concerns like dilution of the service where the volume will be less than the acceptable standards, the increase in mortality and morbidity, and failure to obtain personalized medicine at a reasonable cost. Therefore, we built up this survey questionnaire about those concerns and collected the opinion of expert medical staff in Saudi Arabia who are working in the field of pediatric cardiology. Seventy percent of the responders vs. $25 \%$ recommend the centralization of the PCS as the solution for the above concerns, and $94 \%$ recommend sticking to the globally accepted criteria when issuing the license of the centers providing PCS including the volume of patients in each center, and minimum multidisciplinary facilities in terms of resources, services, and personnel.

\section{Keywords: pediatric cardiology services, centralization, regionalization, birth rate, waiting list, patient load, quality,} Saudi Arabia

\section{INTRODUCTION}

The population of the Kingdom of Saudi Arabia (KSA) exceeds 35 million people (1); however, the birth rate continues to show a decreasing pattern in the recent report of the World Bank (2).

The recently reported prevalence of congenital heart disease in KSA looks to be higher than reported in other populations in the Middle East and Europe (3). We explain that this relative prevalence increase, when compared to neighboring countries, is due to an increase in PCS in a well-structured system, while when compared with European countries it might be related to higher inbreeding and fertility in KSA compared to European countries. In the presence of a non-structured increase in these centers, we expect to face the same global issues that emerged in comparable situations (4), those issues including the concern of dilution of the service where the volume will be less than the acceptable standards (5), the increase in mortality and morbidity (6), and failure to maintain quality medicine at a reasonable cost (7). The institution of more centers mandates the presence of all comprehensive hospital practices that must run 24/7/365. These include all levels of urgency as well as all other specialties of the hospital system (including radiology, laboratory medicine, pharmacy, and blood bank) (4), which could represent an unreasonable load to the health system. These concerns are studied in many developed countries and they consider the centralization of the PCS to a few centers a practical solution for these concerns (6-8). 
The concept "centralization" in our survey refers to a process of concentration of resources, which includes sophisticated infrastructures, qualified staff, well-equipped materials, continuously updated knowledge, and a well-structured research system. This process includes the globalization of low volume centers into fewer but highly specialized and larger volume centers distributed in 5 provinces in KSA within the so-called concept of "regionalization" (4). These 5 major centers offer all non-interventional and almost all interventional PCS for their own citizens except for very complicated surgeries and interventions such as Norwood surgery, ECMO, and heart transplantation are kept in the capital city (Riyadh) or in addition to Jeddah.

The process of centralization should keep the current basic pediatric cardiology services (clinical/echocardiography) in the peripheral cities of KSA and keep an open referral channel for advanced PCS in these proposed 5 major centers.

Therefore, we build up this survey questionnaire about those concerns, to collect the opinion of expert medical staff in Saudi Arabia who are working in the field of pediatric cardiology.

\section{METHOD}

Using a secured Internet-based survey (google forms at www.google.com, see attachment 1) we used this form to collect the responses as well as to extract the results and data analysis.

From the total of 175 licensed consultants (cardiologists and surgeons), we sent the Google form to 150 consultants, and 106 responded (95 pediatric cardiology consultants and 11 pediatric cardiac surgeon consultants).

\section{RESULTS}

Data are presented as percentages for nominal variables, or ranges for continuous variables.

\section{Demographics}

The questionnaire was sent to 150 PCC/PCSC, of whom 106 responded to the questionnaire, 95 were pediatric cardiologists, and 11 were pediatric cardiac surgeons. The response rate was $71 \%$ among the PCC/PCSC.

The summary of demographics is illustrated in Table $\mathbf{1}$ and the summary of the answers is illustrated in Table 2.

Most of the responders (67\%) had completed more than 10 years of experience in the field of pediatric cardiology.

\section{The Pediatric Cardiology Service Centralization}

Among the responders, the majority (70\%) had considered doing centralization of the PCS in the centers of the main 5 KSA provinces as a strategic plan and the same percentage declared no need for the institution of further centers. Moreover, about $46 \%$ thought some centers would be closed due to the

Abbreviations: KSA, Kingdom of Saudi Arabia; PCC/PCSC, pediatric cardiology consultants and pediatric cardiac surgeons consultants; PCS, pediatric cardiology services.
TABLE 1 | Showed the participants characters regarding their field of practice and also the length of experience.

\begin{tabular}{lll}
\hline Specialty & $\begin{array}{l}90.5 \% \text { (95 participants) } \\
\text { Pediatric Cardiologists }\end{array}$ & $\begin{array}{l}9.5 \% \text { (11 participants) } \\
\text { Pediatric Cardiology surgeons }\end{array}$ \\
\hline Experience & $\begin{array}{l}33 \% \text { (35 participants) } \\
<10 \text { years }\end{array}$ & $\begin{array}{l}67 \%(71 \text { participants) } \\
>10 \text { years }\end{array}$ \\
\hline
\end{tabular}

It showing clearly most of them has long experience in the field.

health transformation plan. The vast majority (94\%) strictly recommended sticking to the globally accepted criteria when issuing the license of the centers providing PCS. About $71 \%$ of the responders thought that the patient's waiting lists were coming down, and $56 \%$ of the responders mentioned that the lists of new cases were also coming down. A total of $41 \%$ were aware that the birth rate in KSA is decreasing, whereas 39\% thought that it is increasing.

The summary of these responses is illustrated in Table 2.

\section{DISCUSSION}

The majority (70\%) of responders expect that the centralization of PCS in the centers of each province will improve the outcome of these services and decrease morbidity and mortality as it was proved in many registries and reports in Europe (6) and the United States (4). For example, in Sweden, regionalization of care from 4 to 2 centers was associated with a decline in surgical mortality from 9.5 to $1.9 \%$ (6). The participants clearly stated that there was no need for more PCS centers and $46 \%$ of the responders were thinking in advance and expecting that some centers might be globalized especially with the health transformation strategy adopted by the ministry of health in KSA, which is going in harmony with the discussed survey in the centralization of PCS.

As the vast majority of the responders (94\%) strongly recommend applying the globally accepted criteria (9) for any centers providing PCS, therefore the only way to achieve this recommendation is to centralize these services to a few centers that are distributed according to population density. In 2011, the United Kingdom-Bristol Royal Infirmary inquiry included a massive survey and review study of physicians, hospitals, the public, and policymakers. It resulted in the recommendation to decrease the number of centers providing PCS from 11 to 7 in order to improve the quality of care (10). In 2016, the review of the changes found that health care outcomes were improved (9). Despite an annual increase in the number of cases operated between 2000 and 2009 from 2,283 to 3,939, the 30-day death rate dropped from 4.3 to $2.6 \%$ of cases (9). The improvement extended to cover several areas of care, for example, numbers of medical surgical and nursing staff, patient satisfaction, facilities expansion, complex surgical procedure addition, and others (9).

On the other hand, the trainees should be exposed to a good volume of patients and procedures to produce a good outcome in pediatric cardiology training programs (5). The latter principle is a rapidly growing important criterion for any center providing PCS. The Bristol Royal Infirmary inquiry report documented 
TABLE 2 | Showing the summary of the participant responses to our main survey questions.

\begin{tabular}{|c|c|c|c|}
\hline Question & Yes & No & Don't know \\
\hline Do you think we should do centralization? & $70 \%(75)$ & $22 \%(23)$ & $8 \%(8)$ \\
\hline Do we need more centers? & $25 \%(26)$ & $70 \%(73)$ & $5 \%(5)$ \\
\hline With changes in health sector due to health transformation plan, are there centers which will close? & $46 \%(49)$ & $24 \%(25)$ & $30 \%(32)$ \\
\hline Is it ok for any hospital to provide the service regardless of the number of criteria? & $4 \%(4)$ & $94 \%(100)$ & $2 \%(2)$ \\
\hline Is the waiting list coming down? & $71 \%(75)$ & $24 \%(26)$ & $5 \%(5)$ \\
\hline Is the number of new cases coming down? & $56 \%(59)$ & $43 \%(46)$ & $2 \%(2)$ \\
\hline Is the birth rate in Saudi Arabia coming down? & $41 \%(43)$ & $39 \%(42)$ & $20 \%(21)$ \\
\hline Are the fellows exposed to enough numbers? & $41 \%(43)$ & $38 \%(40)$ & $21 \%(22)$ \\
\hline
\end{tabular}

inadequate standards of care and a higher mortality rate at one center (10) due to deficiency of some accreditation criteria including the appropriate volume of patients. However, in our survey, only $41 \%$ of the responders stated that the trainees are exposed to acceptable patient volume. Therefore, this will also be another supportive evidence that makes centralization of PCS as a gold standard to improve the outcome in training programs.

The centralization of PCS could serve as a model for the coordination of other low volumes, such as high complexity specialties (11).

\section{STRENGTH AND LIMITATIONS}

One of the novel aspects of this paper is to bring light into understanding the current situation of the pediatric cardiac service in KSA through the opinions of experienced medical staff in the field of PCS. Such opinions could be used in better planning for the future of the pediatric cardiac service in KSA.

As this survey depends on personal experience, which represents subjective rather than objective judgments, this could be considered as a point of weakness. However, the results of this survey are supported by well-standardized international studies in different countries $(4,6-8)$, as well as could be considered a pilot introduction to produce more national and regional objective evidence in the future.

\section{CONCLUSION}

Centralization of PCS to reasonably limited centers within the main provinces according to population density will provide specific health assistance in the pediatric cardiology field in

\section{REFERENCES}

1. Latest Statistical Releases. General Authority for Statistics (2021). Available online at: https://www.stats.gov.sa/en/statistics- overview

2. Fertility rate, total (births per woman)-Saudi Arabia | Data. (2021). Available online at: https://data.worldbank.org/indicator/SP.DYN.TFRT.IN?locations= SA

3. Majeed-Saidan MA, Atiyah M, Ammari AN, AlHashem AM, Rakaf MS, Shoukri MM, et al. Patterns, prevalence, risk factors, and survival of newborns with congenital heart defects in a Saudi population: a three-year, cohort casecontrol study. J Congenit Cardiol. (2019) 3:2. doi: 10.1186/s40949-019-0023-8
KSA and other Middle Eastern countries. This method might produce a good outcome for pediatric cardiology, training programs, and research background as well as a cost-effective strategy and a quality improvement tool to provide PCS. This conclusion is supported by the results of our survey questionnaire and by well-standardized international studies as well.

\section{DATA AVAILABILITY STATEMENT}

The raw data supporting the conclusions of this article will be made available by the authors, without undue reservation.

\section{ETHICS STATEMENT}

The studies involving human participants were reviewed and approved by King Fahad Medical City, Institutional review board with IRB and FWA registration numbers: IRB00010471 and FWA00018774. The patients/participants provided their written informed consent to participate in this study.

\section{AUTHOR CONTRIBUTIONS}

All authors listed have made a substantial, direct, and intellectual contribution to the work and approved it for publication.

\section{ACKNOWLEDGMENTS}

We would like to thank all the responders who gave us very immediate, clear, complete, and appropriate responses. Circulation. (2020) 943-5. doi: 10.1161/CIRCULATIONAHA.119.045542

5. Jacobs JP. Does Volume in a Pediatric Cardiac Surgery Program Impact the Results? (2018). Available online at: https://www.sts.org/ sites/default/files/documents/Thurs A_1124_Does Volume impact the Results_Jacobs v3.pdf\%0Ahttps://ahca.myflorida.com/SCHS/PCTAP/docs/ 102518/JacobsPowerPoint2.pdf

6. Lundström NR, Berggren H, Björkhem G, Jögi P, Sunnegårdh J. Centralization of pediatric heart surgery in Sweden. Pediatr Cardiol. (2000) 21:3537. doi: $10.1007 / \mathrm{s} 002460010079$ 
7. Vonlanthen R, Lodge P, Barkun JS, Farges O, Rogiers X, Soreide $\mathrm{K}$, et al. Toward a consensus on centralization in surgery. Ann Surg. (2018) 268:712-24. doi: 10.1097/SLA.00000000000 02965

8. Bazan VM, Zwischenberger JB, Backer CL. Regionalization of congenital heart surgery: time for a rational approach. Prog Pediatr Cardiol. (2020) 59:101308. doi: 10.1016/j.ppedcard.2020. 101308

9. Qc EG. The Report of the Independent Review of Children's Cardiac Services in Bristol. (2016).

10. Departement of Health. Learning from Bristol: the Department of Health's Response to the Report of the Public Inquiry into Children's heart surgery at the Bristol Royal Infirmary 1984-1995. Pharmaceut J. (2002) 277:122.

11. Welke KF, Pasquali SK, Lin P, Backer CL, Overman DM, Romano JC, et al. Regionalization of congenital heart surgery in the United States. Semin Thorac Cardiovasc Surg. (2019) 32:128-37. doi: 10.1053/j.semtcvs.2019. 09.005
Conflict of Interest: The authors declare that the research was conducted in the absence of any commercial or financial relationships that could be construed as a potential conflict of interest.

Publisher's Note: All claims expressed in this article are solely those of the authors and do not necessarily represent those of their affiliated organizations, or those of the publisher, the editors and the reviewers. Any product that may be evaluated in this article, or claim that may be made by its manufacturer, is not guaranteed or endorsed by the publisher.

Copyright $\odot 2022$ Tamimi, AlGonaid, AlMashham and Almashham. This is an open-access article distributed under the terms of the Creative Commons Attribution License (CC BY). The use, distribution or reproduction in other forums is permitted, provided the original author(s) and the copyright owner(s) are credited and that the original publication in this journal is cited, in accordance with accepted academic practice. No use, distribution or reproduction is permitted which does not comply with these terms. 